\title{
Use of non-invasive stimulation in movement disorders: a critical review
}

\author{
O uso da estimulação não-invasiva em distúrbios do movimento: uma revisão crítica

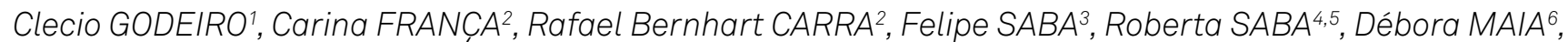 \\ Pedro BRANDÃO ${ }^{7}$, Nasser ALLAMㄱ, Carlos R. M. RIEDER ${ }^{8}$, Fernando Cini FREITAS ${ }^{9}$, Tamine CAPATO2,10, \\ Mariana SPITZ11, Danilo Donizete de FARIA4,5, Marcela CORDELLINI'2, Beatriz A. A. G. VEIGA ${ }^{5}$, Maria Sheila \\ G. ROCHA ${ }^{13}$, Ricardo MACIEL ${ }^{6}$, Lucio B. DE MELO ${ }^{14}$, Patricia D. S. MÖLLER ${ }^{15}$, Magno R. R. JÚNIOR ${ }^{16}$, Luís H. T. \\ FORNARI ${ }^{17}$, Carlos E. MANTESE ${ }^{18}$, Egberto Reis BARBOSA², Renato P. MUNHOZ ${ }^{19,20}$, Marcus Vinicius DELLA \\ COLETTA ${ }^{21}$, Rubens Gisbert CURY2, on behalf of Neuromodulation for Movement Disorders Study Group \\ Brazilian Academy of Neurology
}

\begin{abstract}
Background: Noninvasive stimulation has been widely used in the past 30 years to study and treat a large number of neurological diseases, including movement disorders. Objective: In this critical review, we illustrate the rationale for use of these techniques in movement disorders and summarize the best medical evidence based on the main clinical trials performed to date. Methods: A nationally representative group of experts performed a comprehensive review of the literature in order to analyze the key clinical decision-making factors driving
\end{abstract}

\footnotetext{
1 Universidade Federal do Rio Grande do Norte, Departamento de Medicina Integrada, Natal RN, Brazil.

${ }^{2}$ Universidade de São Paulo, Faculdade de Medicina, Departamento de Neurologia, Centro de Distúrbios do Movimento, São Paulo SP, Brazil.

${ }^{3}$ Universidade Estadual de Campinas, São Paulo SP, Brazil.

${ }^{4}$ Hospital do Servidor Público Estadual, São Paulo SP, Brazil.

5Universidade Federal de São Paulo, São Paulo SP, Brazil.

${ }^{6}$ Universidade Federal de Minas Gerais, Departamento de Medicina Interna, Unidade de Distúrbios do Movimento, Belo Horizonte MG, Brazil.

־Universidade de Brasília, Laboratório de Neurociências e Comportamento, Brasília DF, Brazil.

${ }^{8}$ Universidade Federal de Ciências da Saúde de Porto Alegre, Porto Alegre RS, Brazil.

${ }^{9}$ Hospital Governador Celso Ramos, Serviço de Neurologia, Florianópolis SC, Brazil.

${ }^{10}$ Radboud University Medical Centre, Donders Institute for Brain, Cognition and Behavior, Department of Neurology, Nijmegen, Netherlands.

"Universidade do Estado do Rio de Janeiro, Unidade de Distúrbios do Movimento, Rio de Janeiro RJ, Brazil.

${ }^{12}$ Instituto de Neurologia de Curitiba, Curitiba PR, Brazil.

${ }^{13}$ Hospital Santa Marcelina, Departamento de Neurologia e Neurocirurgia Funcional, São Paulo SP, Brazil.

${ }_{14}$ Universidade Estadual de Londrina, Serviço de Neurologia, Londrina PR, Brazil.

${ }^{15}$ Hospital da Criança de Brasília José Alencar, Unidade Pediátrica de Distúrbios do Movimento, Brasília DF, Brazil.

${ }^{16}$ Universidade Federal do Maranhão, Hospital Universitário, São Luís MA, Brazil.

${ }^{17}$ Santa Casa de Misericórdia de Porto Alegre, Departamento de Neurologia, Porto Alegre RS, Brazil.

${ }^{18}$ Hospital Mãe de Deus, Serviço de Neurologia, Porto Alegre RS, Brazil.

${ }^{19}$ University of Toronto, Toronto Western Hospital - UHN, Division of Neurology, Morton and Gloria Shulman Movement Disorders Centre and Edmond J. Safra Program in Parkinson's Disease, Toronto ON, Canada.

${ }^{20}$ Krembil Brain Institute, Toronto ON, Canada.

${ }^{21}$ Universidade do Estado do Amazonas, Manaus AM, Brazil.

Clecio GODEIRO (D) https://orcid.org/0000-0002-4312-1633; Carina FRANÇA (D) https://orcid.org/0000-0001-8036-2439; Rafael Bernhart CARRA (D) https:// orcid.org/0000-0001-6898-8455; Felipe SABA (ID https://orcid.org/0000-0002-5538-6997; Roberta SABA (DD https://orcid.org/0000-0002-6556-8145; Débora MAIA (D) https://orcid.org/0000-0003-3089-2911; Pedro BRANDÃO (D) https://orcid.org/0000-0002-5537-0186; Nasser ALLAM (D) https://orcid. org/0000-0002-4041-5185; Carlos R. M. RIEDER (D) https://orcid.org/0000-0003-2950-7211; Fernando Cini FREITAS (D) https://orcid.org/0000-0001-73972554; Tamine CAPATO (iD https://orcid.org/0000-0003-4235-4141; Mariana SPITZ (D) https://orcid.org/0000-0001-7548-2313; Danilo Donizete de FARIA (iD https://orcid.org/0000-0003-4336-5715; Marcela CORDELLINI https://orcid.org/0000-0002-1603-1990; Beatriz A. A. G. VEIGA https://orcid.org/0000-00018591-348X; Maria Sheila G. ROCHA (DD https://orcid.org/0000-0003-4312-3994; Ricardo MACIEL (D https://orcid.org/0000-0003-0027-280X; Lucio B. DE MELO (D) https://orcid.org/0000-0002-7946-5446; Patricia D. S. MÖLLER (1D https://orcid.org/0000-0003-1246-8906; Magno R. R. JÚNIOR (D) https://orcid.org/00000001-9300-4972; Luís H. T. FORNARI (1) https://orcid.org/0000-0001-5244-9393; Carlos E. MANTESE (1D https://orcid.org/0000-0002-8306-803X; Egberto Reis BARBOSA (iD https://orcid.org/0000-0002-6996-9130; Renato P. MUNHOZ (iD https://orcid.org/0000-0002-4783-4067; Marcus Vinicius DELLA COLETTA (iD) https://orcid.org/0000-0002-3368-8492; Rubens Gisbert CURY (D) https://orcid.org/0000-0001-6305-3327

Correspondence: Rubens Gisbert Cury; Email: rubens_cury@usp.br.

Conflict of interest: There is no conflict of interest to declare.
}

Authors' contributions: $\mathrm{CG}, \mathrm{RGC}$ : conceptualization, validation, writing - original draft; RBC, CF: writing - original draft; FS, RS, DM, PB, NA, CRMR, FCF, TC, MS, DDF, MC, BAAGV, MSGR, RM, LBM, PDSM, MRRJ, LHTF, CEM, ERB, RPM, MVDC: conceptualization, review and editing.

Received on August 13, 2020; Received in its final form on October 13, 2020; Accepted on October 21, 2020. 
transcranial magnetic stimulation (TMS) and transcranial direct current stimulation (tDCS) in movement disorders. Classes of evidence and recommendations were described for each disease. Results: Despite unavoidable heterogeneities and low effect size, TMS is likely to be effective for treating motor symptoms and depression in Parkinson's disease (PD). The efficacy in other movement disorders is unclear. TMS is possibly effective for focal hand dystonia, essential tremor and cerebellar ataxia. Additionally, it is likely to be ineffective in reducing tics in Tourette syndrome. Lastly, tDCS is likely to be effective in improving gait in PD. Conclusions: There is encouraging evidence for the use of noninvasive stimulation on a subset of symptoms in selected movement disorders, although the means to optimize protocols for improving positive outcomes in routine clinical practice remain undetermined. Similarly, the best stimulation paradigms and responder profile need to be investigated in large clinical trials with established therapeutic and assessment paradigms that could also allow genuine long-term benefits to be determined.

Keywords: Parkinson's Disease; Movement Disorders; Transcranial Direct Current Stimulation; Transcranial Magnetic Stimulation.

\section{RESUMO}

Introdução: A estimulação não-invasiva tem sido amplamente utilizada nos últimos 30 anos no estudo e no tratamento de um grande número de doenças neurológicas, incluindo distúrbios do movimento. Objetivos: Nesta revisão crítica, discutimos o embasamento científico do uso da estimulação não-invasiva em distúrbios do movimento e as evidências científicas dos principais ensaios clínicos realizados. Métodos: Um grupo de especialistas realizou uma revisão crítica abrangente da literatura a fim de analisar as principais aplicações da estimulação magnética transcraniana (EMT) e da estimulação transcraniana por corrente contínua (ETCC) em distúrbios do movimento. As classes de evidência e de recomendação foram descritas para cada doença. Resultados: Apesar da grande variabilidade da metodologia e baixo efeito clínico, a EMT é provavelmente eficaz para o tratamento dos sintomas motores e da depressão na doença de Parkinson. A eficácia em outros distúrbios do movimento ainda é incerta. A EMT é possivelmente eficaz para o tratamento da distonia focal da mão, do tremor essencial e da ataxia cerebelar. No entanto, é provavelmente ineficaz na redução dos tiques na síndrome de Tourette. Finalmente, a ETCC é provavelmente eficaz na melhora da marcha na doença de Parkinson. Conclusões: As evidências até o momento sugerem que a estimulação não-invasiva pode ser benéfica para o alívio de alguns sintomas em determinados distúrbios do movimento como a doença de Parkinson, o tremor essencial, a distonia e a ataxia. Os protocolos de aplicação e paradigmas de estimulação ainda precisam ser investigados em ensaios clínicos maiores, assim como os seus efeitos a longo prazo.

Palavras-chave: Doença de Parkinson; Distúrbios do Movimento; Estimulação Transcraniana por Corrente Direta; Estimulação Magnética Transcraniana.

\section{INTRODUCTION}

Noninvasive stimulation is increasingly used to study brain function in movement disorders, to explore therapeutic options in orphan diseases (such ataxia) and as adjuvant therapy in conditions such as dystonia and Parkinson's disease $(\mathrm{PD})^{1}$. Two main techniques are available for human noninvasive brain stimulation: transcranial magnetic stimulation (TMS) and transcranial direct current stimulation (tDCS). These neuromodulatory techniques are applied over selected cortical areas to modulate specific electrical activity in cortical-subcortical networks that are supposedly related to a given set of symptoms ${ }^{1}$.

During TMS administration, a short-lasting magnetic field is created in the coil, which induces a relatively focal electrical field in the subjacent cortex (Figure 1). This electrical field can cause depolarization or hyperpolarization of the voltage-gated ion-channels in the cell membranes, which leads to modifications in neuronal activation thresholds ${ }^{2}$. The TMS technique has distinct variables, such as stimulus amplitude, pulse waveform, pulse duration and the diameter and shape of the coil ${ }^{3}$. The interaction of TMS pulse and brain tissue is complex, depending on cortical morphology, tissue conductivity, design of the TMS coil and the current running through it. In general, low $(\leq 1 \mathrm{~Hz})$ or high $(\geq 5 \mathrm{~Hz})$ frequency rTMS is used to, respectively, decrease or increase cortical brain excitability ${ }^{3}$. Repetitive TMS (rTMS) refers to the application of trains of repeated magnetic pulses delivered to the scalp. Repetitive stimuli can lead to a build-up of effects that might enhance the therapeutic benefits gained from a single application through reduction of the action potential threshold, response enhancement and neuroplasticity due to generation of multiple action potential ${ }^{3}$. In order to produce cumulative effects, besides rTMS trains, several sessions are usually needed, which in most cases are given daily for 5,10 or more days ${ }^{1,4}$. An alternative use of rTMS has been developed, modelled on theta burst stimulation (TBS) in animals, a technique that comprises short, repeated bursts of TMS pulse at $50 \mathrm{~Hz}$. This is a potentially useful option in movement disorder treatment, and it is discussed later in this paper ${ }^{3}$. TMS is now FDA-approved, as a treatment for patients with depression (unipolar or bipolar), migraine and obsessive-compulsive disorder.

Transcranial direct current stimulation (tDCS) modulates spontaneous neuronal activity through an electrical current applied through a pair of electrodes placed on the scalp. tDCS does not facilitate massive synchronized discharge of action potentials, as TMS does, but it induces polarity-specific changes of resting membrane potential ${ }^{5}$. Cortical excitability is diminished through cathodal stimulation (neuronal hyperpolarization), whilst anodal stimulation increases excitability by means of depolarizing neurons. Although tDCS has been 


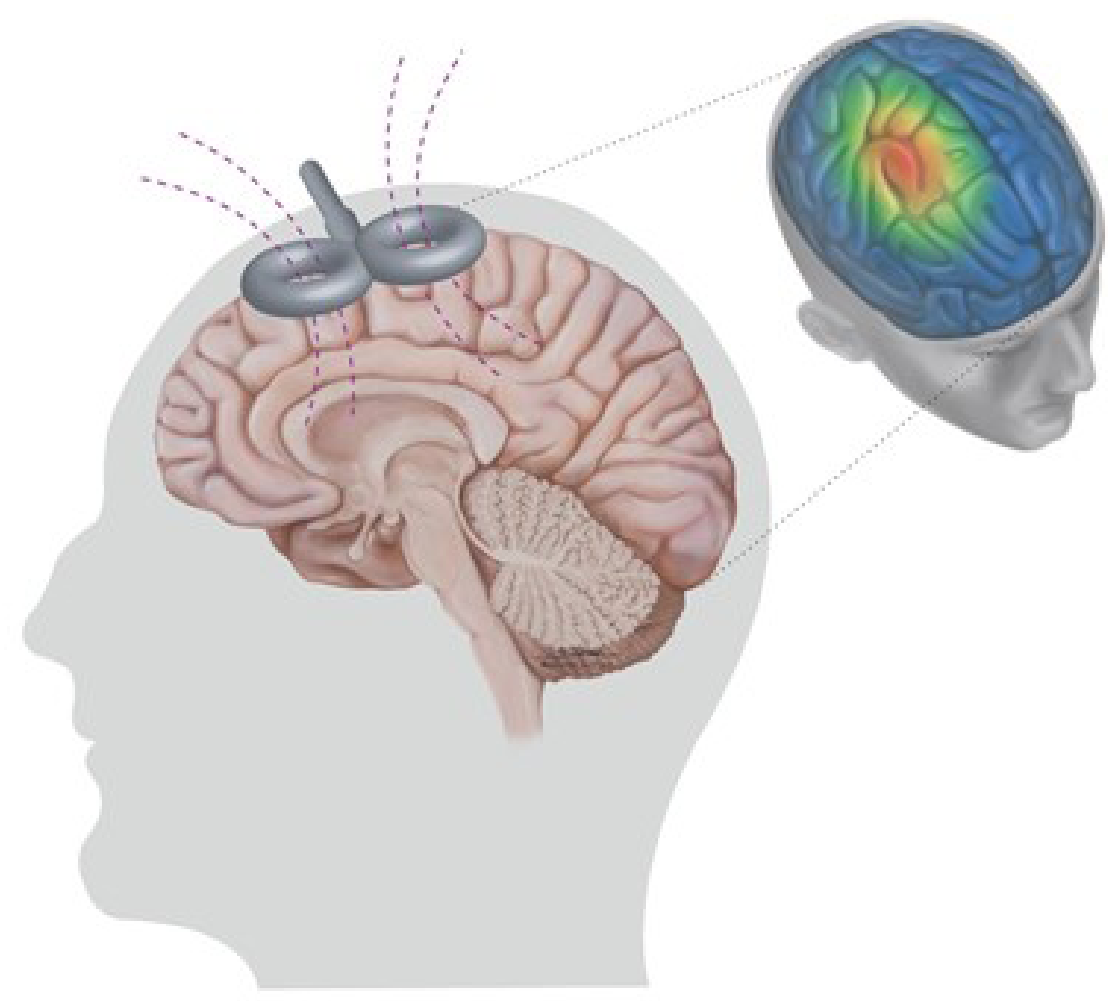

Figure 1. Brain activation by means of transcranial magnetic stimulation. The magnetic field in the transcranial magnetic stimulation coil (left) and the schematic representation of the electrical current induced in the brain (right).

studied less in relation to movement disorders, this review will highlight the most relevant studies that have applied these techniques in clinical trials.

\section{Why use noninvasive stimulation in movement}

\section{disorders?}

Despite the fact that the basal ganglia, the core of movement disorder pathophysiology, cannot be reached directly by tDCS or TMS, stimulation over an appropriate cortical region that is part of the basal ganglia circuitry could influence activity within these loops and potentially produce clinical benefit ${ }^{4}$. Thus, the therapeutic background mechanisms for the use of these techniques have both local properties (over well-established cortical areas associated with movement disorders) and remote properties. For example, stimulation of the supplementary motor area (SMA) has been associated with improvement of freezing of gait (FoG) in $\mathrm{PD}^{6}$. Because the SMA is a pivotal area for gait initiation and is activated less in PD with FoG than in PD without FoG, its direct stimulation makes sense and has been specifically studied?

The distant, indirect effects of stimulation have been recently studied using noninvasive and invasive techniques (deep brain stimulation, DBS) in movement disorders. For example, parkinsonian patients respond better to subthalamic nucleus (STN) DBS when the stimulation site is functionally connected to the SMA (mainly dorsal STN projections) ${ }^{8}$, while tics in patients with Tourette syndrome (TS) are better controlled when thalamic stimulation is more densely connected with the cingulate and frontal middle gyrus'. TMS of the human primary motor cortex (M1) induces release of dopamine in the ipsilateral putamen, as detected by [11C]raclopride $\mathrm{PET}^{10}$. Additionally, magnetic stimulation of the preSMA significantly affects intrinsic connectivity between the pre-SMA and the striatum observed in functional MRI paradigms ${ }^{11}$. Besides metabolic and functional influences on basal ganglia, motor TMS suppresses pathological beta frequency oscillations in the STN in PD patients ${ }^{12}$. Taken together, the local and remote effects of cortical stimulation would be able to reset abnormal activity in one or more nodes of the altered distributed network and ultimately improve the symptoms of the underlying movement disorder. In the following sections, we analyze the main clinical studies on this matter to date.

\section{METHODS}

A nationally representative group of experts performed a comprehensive analysis of the literature in order to develop a critical review on key clinical decision-making factors driving noninvasive modulation in movement disorders.

The methodological quality of the trials reviewed was classified in accordance with the PEDro scale, which includes ten criteria (internal validity with eight criteria and statistical analysis with two criteria; Supplementary File 1$)^{13}$. Classes 
of evidence and recommendations were described in accordance with the American Academy of Neurology's classification for rating therapeutic studies, whenever possible (Supplementary File 2 and 3) ${ }^{14}$. Furthermore, the aim of the present review was to analyze the relevance and applicability of the evidence to the targeted patient group and the likelihood of a clinical impact through the intervention.

Studies were identified by searching electronic databases and scanning the reference lists of articles. Only articles in English were included, through systematically searching the Medline, Embase and Google Scholar databases. The last search was run on July 19, 2020. The reference and citation lists of relevant studies were manually screened for potential eligible articles. We searched for the terms "Parkinson's disease", "dystonia", "tremor", "ataxia" and "Tourette syndrome", in combination with terms describing the type of stimulation (TMS and tDCS). We included published reports of clinical trials that examined the clinical effects after neuromodulation interventions (classes I, II, III and IV of evidence). For the sake of conciseness, we did not include studies already present in or preceding the meta-analysis and systematic reviews that we reviewed.

\section{RESULTS}

\section{Parkinson's disease}

Noninvasive stimulation has been studied in PD for almost three decades, and this has resulted in a much larger amount of clinical exploration than in relation to the other diseases discussed in this review. In PD, our search revealed 85 trials using TMS and 37 using tDCS. Given that many recent metaanalyses and systematic reviews are available, only recent non-included trials were selected for individual review, totaling nine studies (Table 1). PEDro scores ranged from 5 to 9 ( mean $=8.0 \pm 1.4$ ), with six high-quality studies (PEDro 8 or 9).

\section{Transcranial magnetic stimulation}

The motor effects of rTMS have been subjected to several meta-analyses. The most recent of these included 28 randomized controlled or crossover trials up to July 2019, with 25 trials evaluating motor symptoms in a total of 787 patients $^{15}$. Only five rTMS studies were published subsequently, and these are discussed individually. All forms of rTMS stimulation were found to ameliorate motor symptoms in a statistically significant manner, even within subgroup analyses. Using UPDRS-III as a standard motor outcome, a quantitative analysis was possible. This showed distinct effect magnitudes, measured using the standard mean difference (SMD). Per stimulation site, the primary motor cortex (M1) had the highest SMD compared with placebo, with 2.22; followed by the dorsal lateral prefrontal cortex (DLPFC) with 1.42; and the SMA and a combination of M1 + DLPFC, both with reported
SMD of $1.27^{15}$. High-frequency rTMS was more effective than low-frequency rTMS. The improvement was greater under off-medication conditions (SMD 2.98) than under on-medication conditions (SMD 1.51) ${ }^{15}$. This is mostly in agreement with a previous 2018 meta-analysis on 23 trials, in which significant motor benefit from high-frequency M1 and SMA stimulation was reported, with greater effect from the former, while non-motor effects were demonstrated using low-frequency rTMS or stimulation over the DLPFC ${ }^{16}$.

Recent trials are in agreement about the motor efficacy of the technique, as measured by means of UPDRS-III, including two positive trials with $20 \mathrm{~Hz}$ rTMS on $\mathrm{M1}^{17}$, one with $10 \mathrm{~Hz}$ on the SMA ${ }^{18}$, and two comparative trials. The first of these comparative trials showed longer-lasting efficacy of $20 \mathrm{~Hz}$ rTMS on M1, compared with $1 \mathrm{~Hz}^{19}$, while the other showed improvement with $5 \mathrm{~Hz}$ only on the pre-SMA, compared with $\mathrm{M}^{20}$.

Dysphagia was evaluated through a single trial, which showed class II evidence of limited improvement after highfrequency rTMS sessions (consisting of 10 daily sessions targeting M1, followed by monthly booster sessions). The improvement of dysphagia was correlated with overall motor improvement ${ }^{21}$. Cerebellum rTMS has been tested as a target for motor improvement in PD, but with disappointing results. Single-session cerebellar $1 \mathrm{~Hz}$ rTMS in 20 patients resulted in minor improvement of upper-limb mobility, but worsening of fine motor movements ${ }^{22}$.

Regarding non-motor symptoms, the most recent metaanalysis with rTMS, on depression in the setting of PD, included eight trials comprising a total of 331 patients $^{15}$. Like non-PD depression patients, left DLPFC stimulation was found to be effective for the improvement of depression scores (SMD 1.64), which was consistent with a previous meta-anal$\mathrm{ysis}^{23}$. Lastly, a recent meta-analysis found that rTMS on the M1 or PFC did not have any significant effect on cognition ${ }^{24}$, while minor cognitive improvement was observed in a later study using $20 \mathrm{~Hz}$ rTMS on bilateral M1, in PD patients with dementia ${ }^{17}$. No study on TMS and PD has described any serious side effects.

\section{Interpretation}

High-frequency rTMS stimulation over M1 is currently the most supported form of rTMS for motor symptoms in PD and is likely to be effective. Other sites and parameters have shown smaller margins of effect so far. High-frequency rTMS DLPFC has already been approved by the FDA for treating major depression in non-PD patients and is likely to be effective for depression in PD patients, thus mirroring what has been established for non-PD patients in this setting.

\section{Theta burst stimulation}

Three studies used cerebellar continuous TBS (cTBS) for levodopa-induced dyskinesias, among a total of 39 patients, 


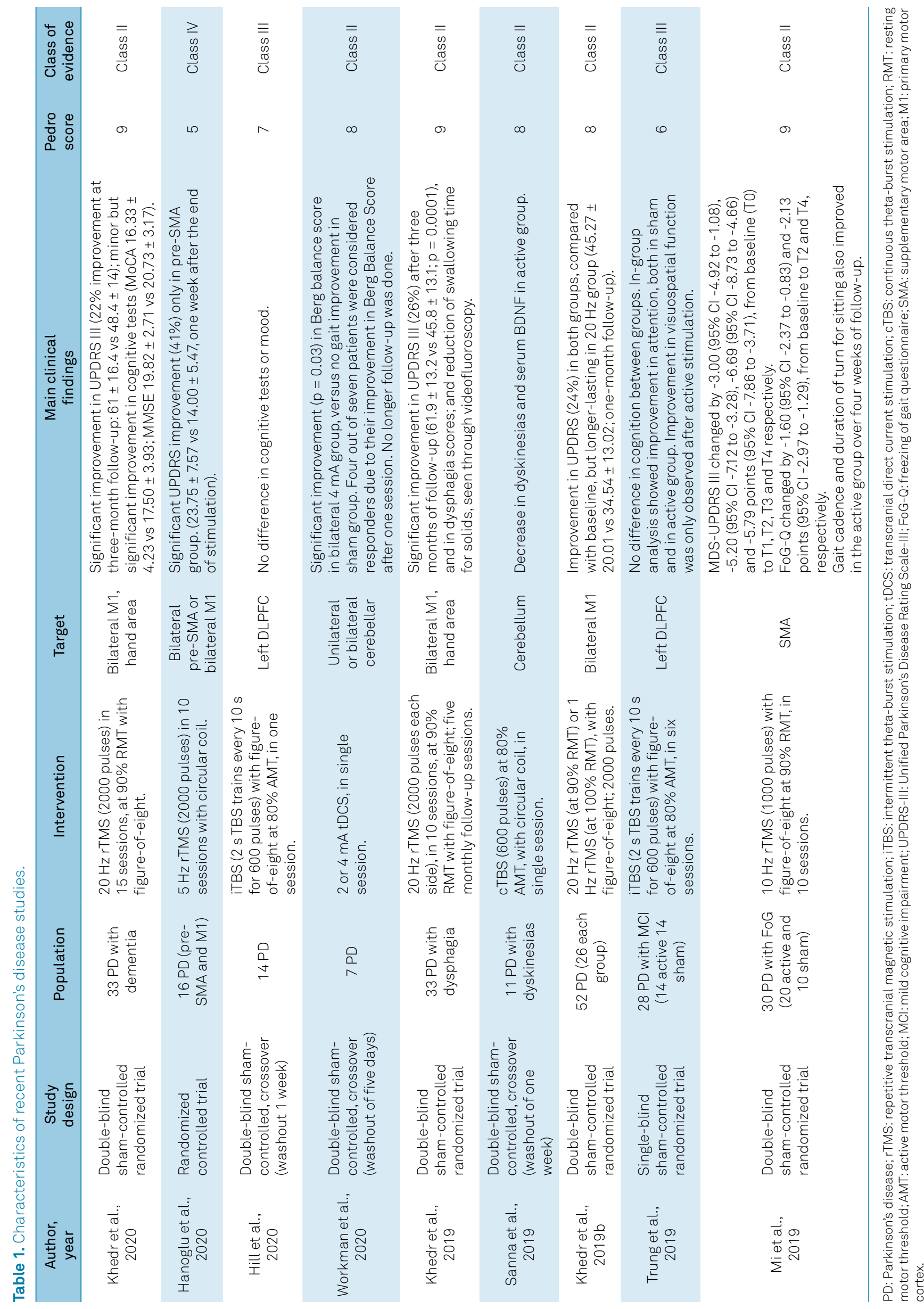


who all showed improvement in dyskinesias after either a single or five sessions ${ }^{22}$. However, cerebellar cTBS did not show any significant effect on tremor ${ }^{22}$. cTBS over M1 had no significant motor effect although when applied over the SMA, a mild yet significant motor improvement after a single session was detected ${ }^{25}$. Intermittent TBS (iTBS) over the premotor cortex (PMC) resulted in no improvement in motor or mood scores $^{26}$. For cognition, single and multiple-session iTBS over the DLPFC failed to elicit any improvement ${ }^{27}$. No study on TBS and PD has described any serious side effects.

\section{Interpretation}

Cerebellar cTBS is likely to be effective for controlling levodopa-induced dyskinesias, but there is currently insuffcient evidence to support the use of TBS to treat any other motor or non-motor symptoms or signs.

\section{Transcranial direct current stimulation}

The most recent systematic review for tDCS and motor symptoms included 29 sham-controlled trials up to July 2019 with a total of 550 patients. Despite the number of studies, the study designs were highly heterogeneous. Both anodal and cathodal stimulation over M1, DLPFC and SMA showed inconsistent and contradictory results, with the sole exception of few distinct multitarget approaches with positive findings for locomotion ${ }^{28}$. A more restricted systematic review analyzed only upper-limb outcomes from 10 studies. The results showed UPDRS improvement after unilateral or bilateral M1 tDCS, especially for bradykinesia. However, these results did not allow the authors to recommend any specific protocol, due to the diverse paradigms found in the studies ${ }^{29}$.

The effect of tDCS on gait was specifically evaluated through a meta-analysis involving 18 sham-controlled trials with a total of 325 PD patients. The results showed that there was an overall positive but small effect size $e^{30}$. Again, the diversity of trial designs limited the interpretation, with single or multiple stimulation targets among PMC, M1, PFC or SMA varying in each trial. However, the positive effect size was homogeneous throughout the studies, and the individual effect size variability was low. Six studies that assessed longterm effects failed to show significance ${ }^{30}$. A recent crossover trial with anodal tDCS over the cerebellum reported improvement in dyskinesia during the active phase, with no other detectable motor improvement ${ }^{22}$.

\section{Interpretation}

Current tDCS application for PD is significantly hampered by significant heterogeneity in the population characteristics, PD stages, stimulation parameters, trial designs and outcome measurements. Thus, deriving a consensus on any set of stimulation procedures is extremely difficult. No recommendation is currently possible for motor symptoms other than gait, for which the method is likely to be effective but with a limited effect size (its use as an add-on therapy is discussed below).

\section{Dystonia}

Dystonia is a syndrome characterized primarily by excessive muscle contractions leading to abnormal postures and involuntary twisting movements ${ }^{31}$. As it represents a heterogenous group of disorders, in this review we will focus on isolated dystonia, given that certain pathophysiological mechanisms have been consistently identified and may have implications for widening the therapeutic strategies, such as noninvasive stimulation ${ }^{31}$.

Three general abnormalities appear to underlie network pathophysiology: loss of inhibition at different levels of the central nervous system leading to overflow phenomena, altered sensory integration and maladaptive synapse plasticity $^{32}$.

The current treatment of dystonia includes selected drugs for specific cases, such as dopa-responsive dystonia, botulinum toxin injections for focal dystonia and surgery, notably DBS. However, new insights into the pathophysiology of dystonia and positive results from invasive neuromodulation trials have shown that this disorder should be seen as a consequence of network malfunction. In dystonia, there is an increased tendency to form aberrant input and output connections, potentially leading to abnormal improper connectivity and ultimately impairment of motor control ${ }^{1}$. As such, dystonia could be potentially responsive to noninvasive neuromodulation strategies.

Here, we selected studies on adults with three forms of focal dystonia: hand dystonia, cranio-cervical dystonia (CCD) and blepharospasm.

\section{Hand dystonia}

Fifteen clinical trials have evaluated the effects of noninvasive stimulation for hand dystonia. These trials consisted of a total of 176 patients with different clinical presentations: writer's cramp (96), musician's dystonia (70), focal hand dystonia (9) and dystonic tremor (1). These studies were heterogenous with regard to methodology, neuromodulation technique and parameters and outcome measurements. Their main findings are summarized in Table 2. In terms of methodological quality, PEDro scores ranged from 3 to $8(6.5 \pm 1.5)$. Three studies had scores $<6$ and were considered to be low quality $^{33-35}$. For the remaining ten studies, seven were classified as moderate and five as high quality with PEDro scores of $6 / 7$ and 8 respectively ${ }^{36-40}$. In fact, most of the trials presented class III or IV evidence and had an exploratory approach to the technique and its clinical outcome.

Most studies have targeted the motor cortex (PMC in six; M1 in five; SMA in one). Regarding the neuromodulation technique, seven studies applied rTMS (four singleblinded, one double-blinded, two open), seven used tDCS (all 
double-blinded), and one used cTBS (one single-blinded). The majority of these studies were performed in a single session and had short follow-up periods.

Overall, a limited number of studies reported clinical improvement, especially with short-term evaluation. An open-label study of rTMS on M1 showed that this method can reinforce deficient intracortical inhibition and may temporarily improve handwriting ${ }^{34}$. These results were reinforced by two other single-blinded trials ${ }^{41,42}$ and one double-blinded trial $^{43}$, in which rTMS of the PMC led to temporary improvement in handwriting. Another target with good response was S1, which induced improvement in writer's cramp, measured by a 20 min writer's task ${ }^{44}$.

Regarding tDCS, only one double-blinded cathodic stimulation reported a good outcome, with an improvement in the effectiveness of rehabilitation in task-specific (musician's) dystonia $^{38}$. A current of $2 \mathrm{~mA}$ was used, applied to the SMA bilaterally during the first $20 \mathrm{~min}$ of a 1 hour sensorimotor rehabilitation program over 10 sessions. In this trial, neuromodulation caused an increase in the effectiveness of rehabilitation of musician's dystonia.

\section{Interpretation}

The evidence presented to date does not provide a high level of recommendation for the use of noninvasive modulation in hand dystonia. So far, studies have presented heterogeneous designs and quality, although interesting positive outcomes have been reported. The most promising target seems to be the PMC. Low-frequency rTMS over the PMC is possibly effective in improving handwriting temporally in FHD (studies with class III evidence). For other types of hand dystonia, including musician's dystonia, there is insufficient evidence to support the use of rTMS or tDCS.

\section{Cranio-cervical dystonia (CCD)}

Regarding CCD, only three clinical trials, consisting of a total of 38 patients, have evaluated the therapeutic effects of noninvasive stimulation (Table 3). PEDro scores ranged from 4 (one low-quality study) to 9 (mean, $7.25 \pm 1.8$ ), while most had scores of up to 7 , which was considered high quality although still presenting class III evidence.

These studies presented heterogeneous techniques and targets: (1) two tTMS in motor cortical areas; and (2) one cTBS in the cerebellum. Koch et al. ${ }^{45}$ performed a doubleblind sham-controlled trial of five sessions per week for two weeks among $18 \mathrm{CD}$ patients with cTBS of the cerebellum bilaterally. They showed that there was a small, but significant improvement in TWRTS in comparison with baseline scores, at the first evaluation after the end of stimulation period (mean $33.6 \pm 4.2$ versus $38.8 \pm 4.1 ; \mathrm{p}=0.008$ ). Another study showed a mild improvement through targeting dPMC and $\mathrm{M1}^{46}$. Although a limited number of case series have reported improvements of CCD scores through tDCS, no formal clinical trial has been performed to date.

Only one double-blinded, sham control study (class III evidence) with noninvasive stimulation has been conducted in relation to blepharospasm ${ }^{47}$. The intervention applied was rTMS to the anterior cingulate cortex, and this led to significant improvements of all clinical outcomes at the end of the active stimulations and at $1 \mathrm{~h}$ afterwards.

\section{Interpretation}

There is insufficient evidence to support or refute the effectiveness of noninvasive stimulation in CCD and blepharospasm, mainly because the samples of patients studied so far have been small, and the overall quality of these studies has been low. Even so, the studies performed have explored targets (such as the cerebellum and the motor cortex) that can be potentially effective for CCD, and larger studies are warranted.

\section{Essential tremor}

Nine studies analyzed the effects of noninvasive stimulation among essential tremor (ET) patients ${ }^{48-56}$. Table 4 displays the characteristics of these studies. There was great variability among them regarding methodological quality. The population was fairly homogeneous, since all the studies included ET patients $(\mathrm{n}=119)$, and five studies also included healthy controls $(n=61)$.

Only one study provided class II evidence; three studies provided class IV, and the remaining five provided class III evidence. PEDro scores ranged from 6 to $10(7.4 \pm 1.5)$. Only one study satisfied all the PEDro score criteria ${ }^{48}$, and six studies scored 6 to $7^{49-53,56}$. Therefore, we considered that the majority of these studies were of moderate/high quality.

Six studies targeted the cerebellum $(\mathrm{n}=80$ ET patients + 33 healthy controls $)^{48,49,51,52,54,56}$, and three targeted the motor cortex ( $\mathrm{n}=33 \mathrm{ET}+28$ healthy controls $)^{50,53,55}$. Only one study used cathodal $\mathrm{tDCS}^{52}$, while the remainder used rTMS: in five, the frequency chosen was $1 \mathrm{~Hz}$, and three used cTBS. The number of sessions in rTMS studies ranged from 1 to 15 (mean = 3.7; SD = 4.8), but five of the eight studies only had one session ${ }^{48-50,53,54}$. In the only tDCS study, the patients received 10 sessions $^{52}$.

The length of the follow-up was quite variable, ranging from $\leq 1$ hour after the end of stimulation (five studies) to different numbers of weeks after completion of the study protocol (four studies), with a maximum follow-up of 12 weeks ${ }^{55}$. Obviously, this lack of uniformity limits the potential for accurate comparison of the data. In the longest follow-up, the improvement in tremor after 15 sessions of 1 $\mathrm{Hz}$ rTMS continued to be present until after eight weeks, but not after twelve weeks ${ }^{55}$. Three studies showed clinical improvements through validated tremor scales after noninvasive stimulation, over periods ranging from 5 min to 12 


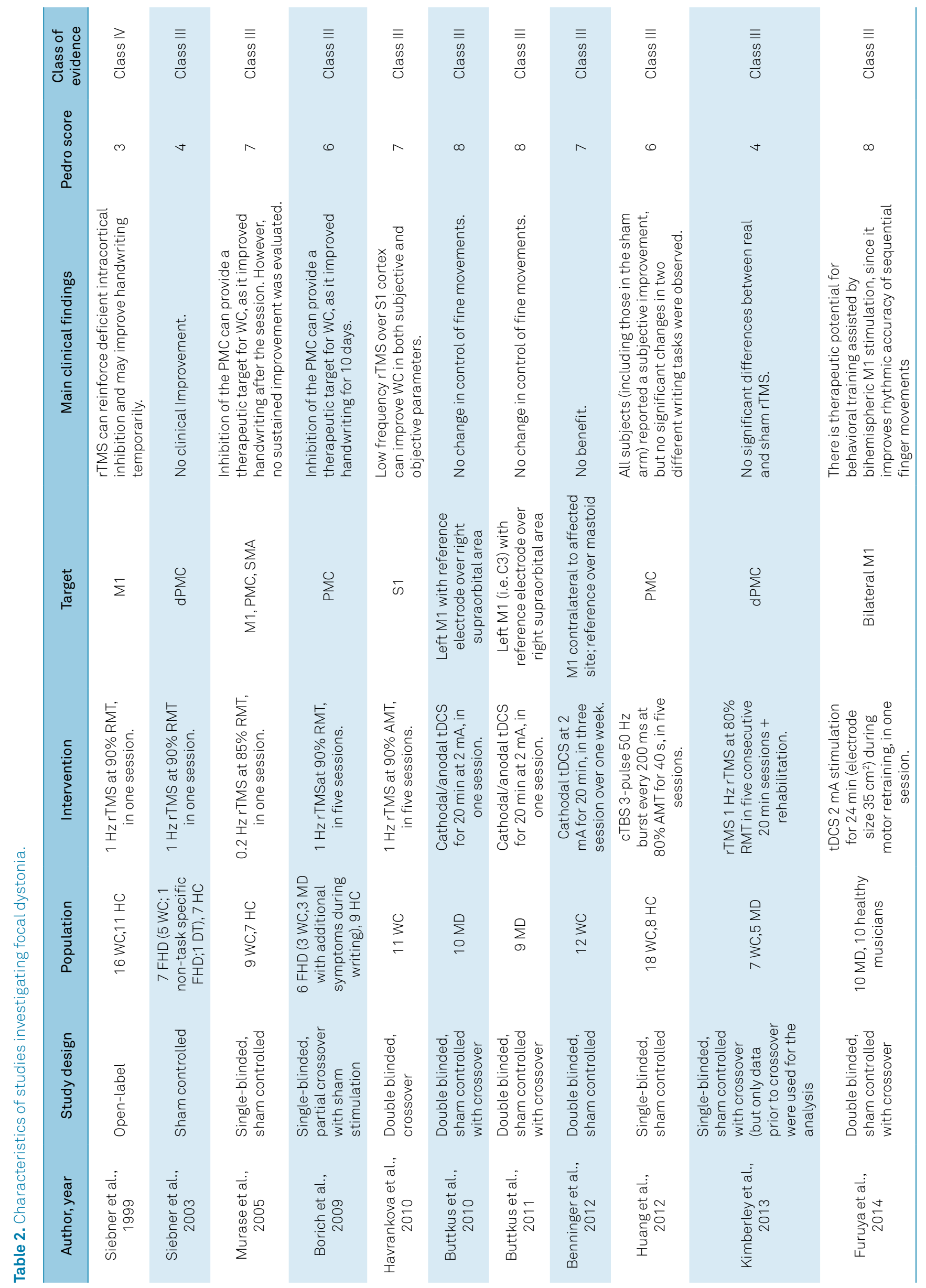



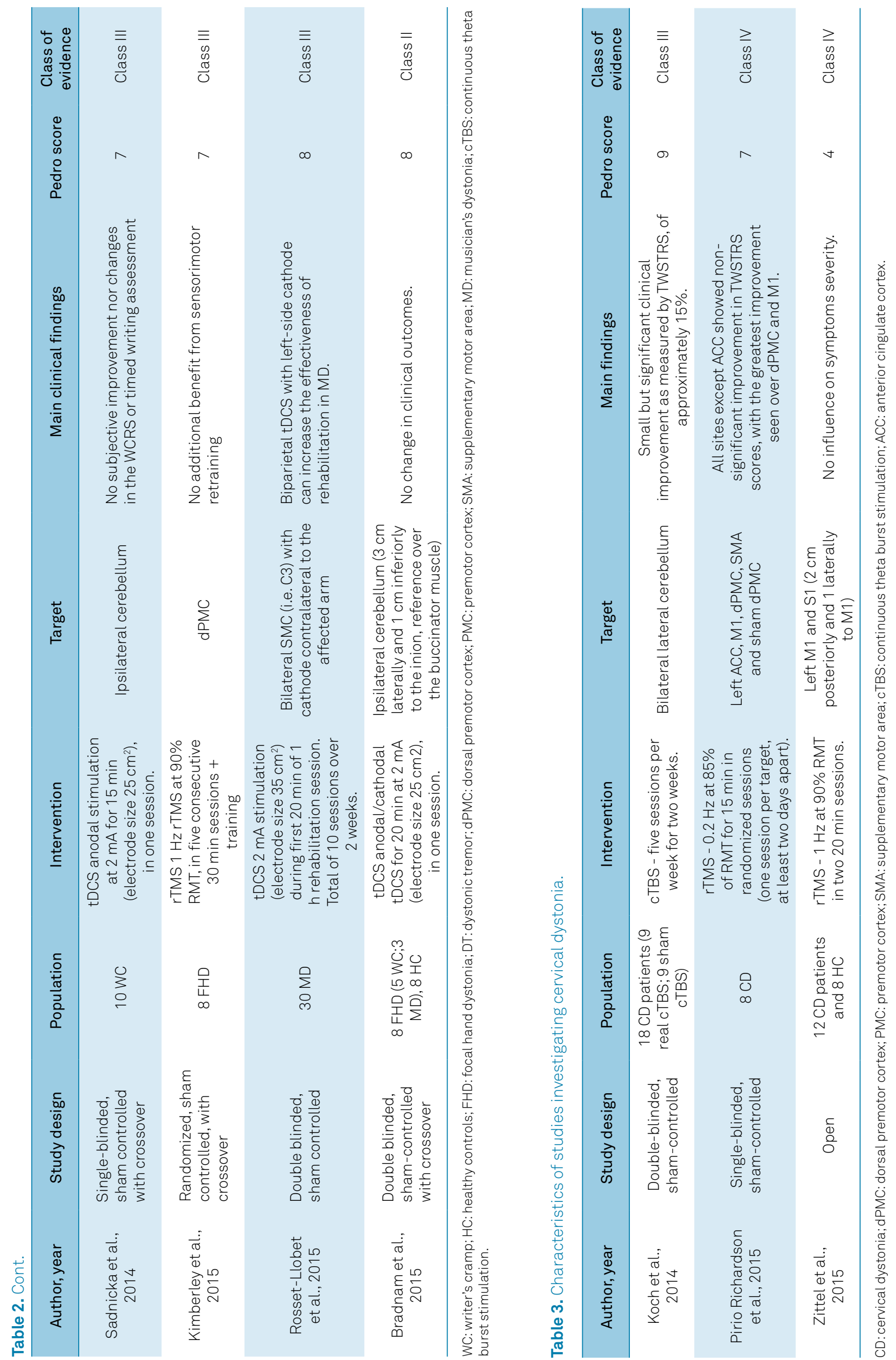


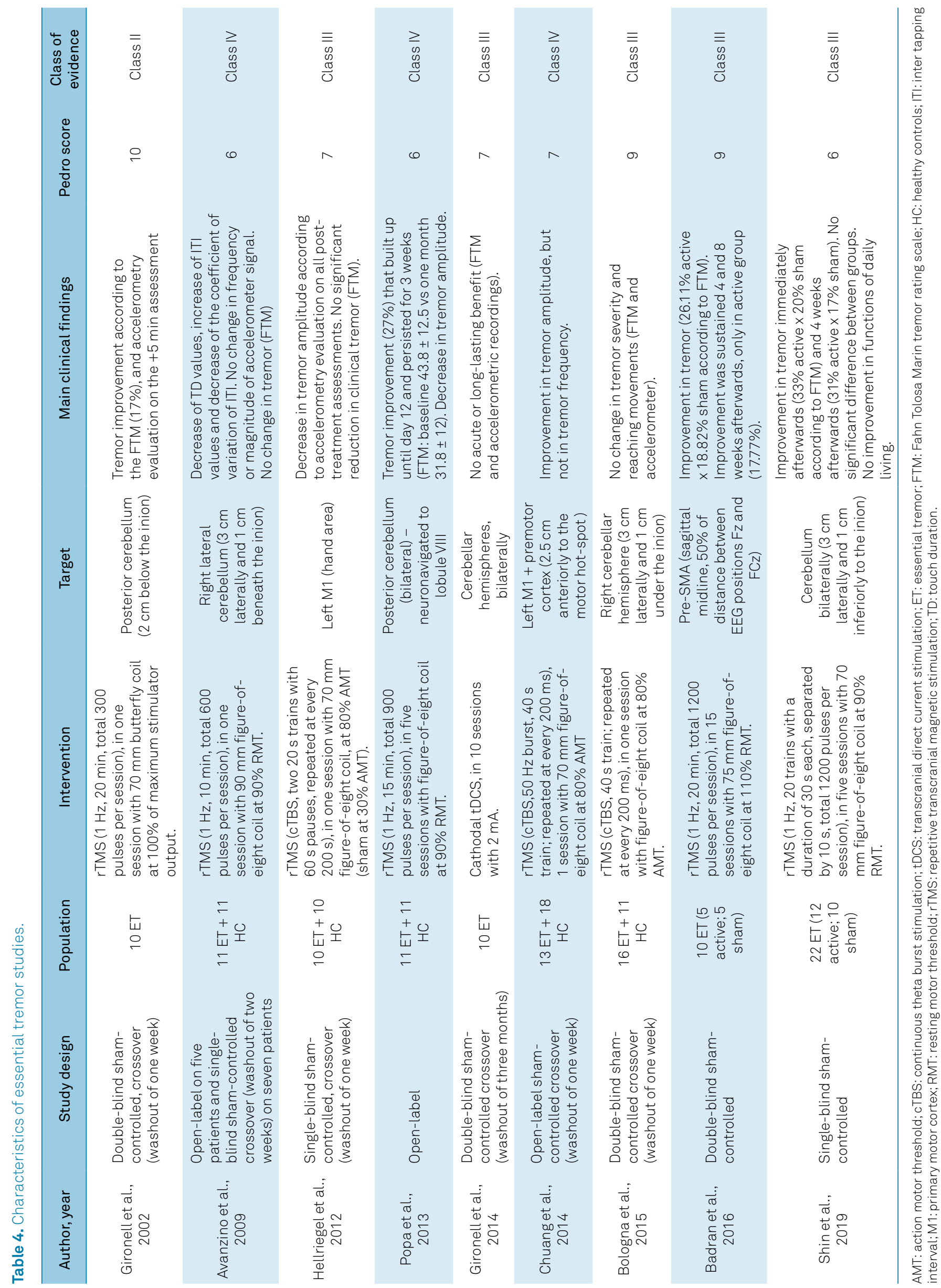


weeks afterwards ${ }^{48,51,55}$. All three used $1 \mathrm{~Hz}$ rTMS: two over the cerebellum and one over the motor cortex ${ }^{48,51,55}$. Seven studies also analyzed tremor characteristics using accelerometric records and, after considering the data from three additional studies, demonstrated positive short-term results ranging from immediate to $40 \mathrm{~min}$ after the procedure ${ }^{49,50,53}$. Two used cTBS over the motor cortex, and one used cerebellar $1 \mathrm{~Hz}$ rTMS $^{53}$. No cTBS study reported any improvement in clinical tremor scales, although two had positive accelerometric outcome data ${ }^{50,53}$. Among the studies with the highest PEDro scores (9-10) $)^{48,54,55}$, two were positive and one was negative. Four studies (three reporting positive accelerometric results) did not mention the presence or absence of side effects, although we believe that side effects are particularly important in clinical trials ${ }^{49,50,53,55}$. Out of the remaining studies, only two reported mild side effects, including one with positive clinical results ${ }^{48,52}$.

\section{Interpretation}

Through gathering the available data, low-frequency rTMS over the cerebellum was seen to be possibly effective in improving tremor in ET (studies with class II and III evidence). The outcomes from tDCS studies do not support any conclusions and, thus, tDCS cannot be recommended ${ }^{52}$. Overall, the heterogeneity of the reports and outcomes is still an obstacle in systematically implementing noninvasive neuromodulation for ET in clinical practice.

\section{Cerebellar ataxia}

Eleven clinical trials included patients with cerebellar ataxia ( $\mathrm{n}=238)$ and evaluated clinical changes after noninvasive stimulation (Table 5). Different ataxia etiologies were included: eight studies included patients with heredodegenerative ataxias $(n=155)^{22,57,58}$, four included patients with sporadic adult-onset ataxia $(n=14)^{58,59}$, three included patients with cerebellar-type multiple-system atrophy $(n=15)^{22,58}$, two included patients with cerebellar ataxia due to stroke $(\mathrm{n}=$ $38)^{60,61}$, two included immune-mediated ataxias $(\mathrm{n}=10)^{22,62}$ and one included cases of ataxia in the setting of cerebral palsy $(n=6)^{63}$. Overall, the population included tended to be heterogeneous throughout the studies, and was limited to a single diagnosis in only four studies (multiple sclerosis in one, stroke in two and cerebral palsy in one $)^{22,62}$.

Two studies provided class IV evidence, while seven provided class III, and two provided class II. PEDro scores ranged from 4 to $9(6.7 \pm 1.9)$, considering all the studies. Studies using tDCS had higher PEDro scores (TMS mean = 6; and tDCS mean = 7.6).

Almost all the studies used the cerebellum as the target; only one study targeted the motor cortex (M1) ${ }^{62}$. Regarding the neuromodulation technique, four studies used singlepulse TMS (two of them were double-blind) ) $^{57,64-66}$, three used rTMS (two double-blind) ${ }^{60-62}$ and five used anodal tDCS (three double-blind $)^{59,63,67-69}$. The chosen stimulation frequency ranged from 1 to $50 \mathrm{~Hz}$, and the number of sessions ranged from one to ten. All five tDCS studies used anodal stimulation, with currents ranging from 1 to $2 \mathrm{~mA}$ and numbers of sessions from one to ten. No study involved maintenance sessions, and none measured long-term effects, although it could be argued that three months of follow-up would constitute long-term in noninvasive neuromodulation.

Only one study, using one session of $1 \mathrm{~mA}$ anodal tDCS, reported no clinical improvement after neuromodulation $^{67}$; the remainder described positive results. Many studies assessed ataxia exclusively through axial measures of gait and balance, and only six studies applied validated ataxia scales $^{57,59,60,66,68,69}$. Both studies with the highest PEDro scores (9 and 10) used anodal tDCS and reported clinical improvement: one with validated scales and the other with gait evaluation. Out of the three studies with PEDro scores of 8, two used anodal tDCS and one used single-pulse TMS ${ }^{22,57,58}$; all of these reported positive outcomes with validated scales.

Reporting of adverse effects was far from ideal, since half of the studies did not mention them ${ }^{59,60,62,66,67,69}$. Among the remaining studies, five reported none ${ }^{57,61,64,65,68}$, while one reported only mild transient side effects after anodal $\mathrm{tDCS}^{63}$.

\section{Interpretation}

Overall, the studies on cerebellar ataxia were of moderate quality, and all but one reported short-term positive results. As such, there is insufficient evidence so far to support the use of rTMS to treat ataxia. Anodal cerebellar tDCS is possibly effective in treating degenerative cerebellar ataxia, but multicenter trials and metanalyses are needed. Considering that cerebellar ataxia is currently an orphan symptom, and that these procedures are noninvasive and safe, off-label treatment could be attempted in selected cases.

\section{Tourette syndrome (TS)}

The pathological mechanism underlying TS is a matter of debate, but some studies have proposed that the primary motor (M1?) cortex and the SMA are hyperexcitable in these patients $^{70}$. These findings have led to the hypothesis that normalizing the excitability of these areas would be a potential treatment for tics. Accordingly, low-frequency rTMS applied over bilateral SMA was found to improve tic severity for up to six months in two open-label trials ${ }^{71,72}$. On the other hand, two randomized controlled trials using the same target did not show any significant improvement in tics after $\mathrm{TMS}^{73,74}$, although in one of them an additional three-week open-label active treatment (for those patients initially randomized to active rTMS) resulted in an overall $29.7 \%$ reduction in tic severity, compared with baseline ${ }^{74}$. Additionally, active TMS induced significant inhibition in the primary motor cortex network. Other targets such as motor and pre-motor cortex were found to have effect on tics in TS patients ${ }^{75,76}$ (Table 6). 


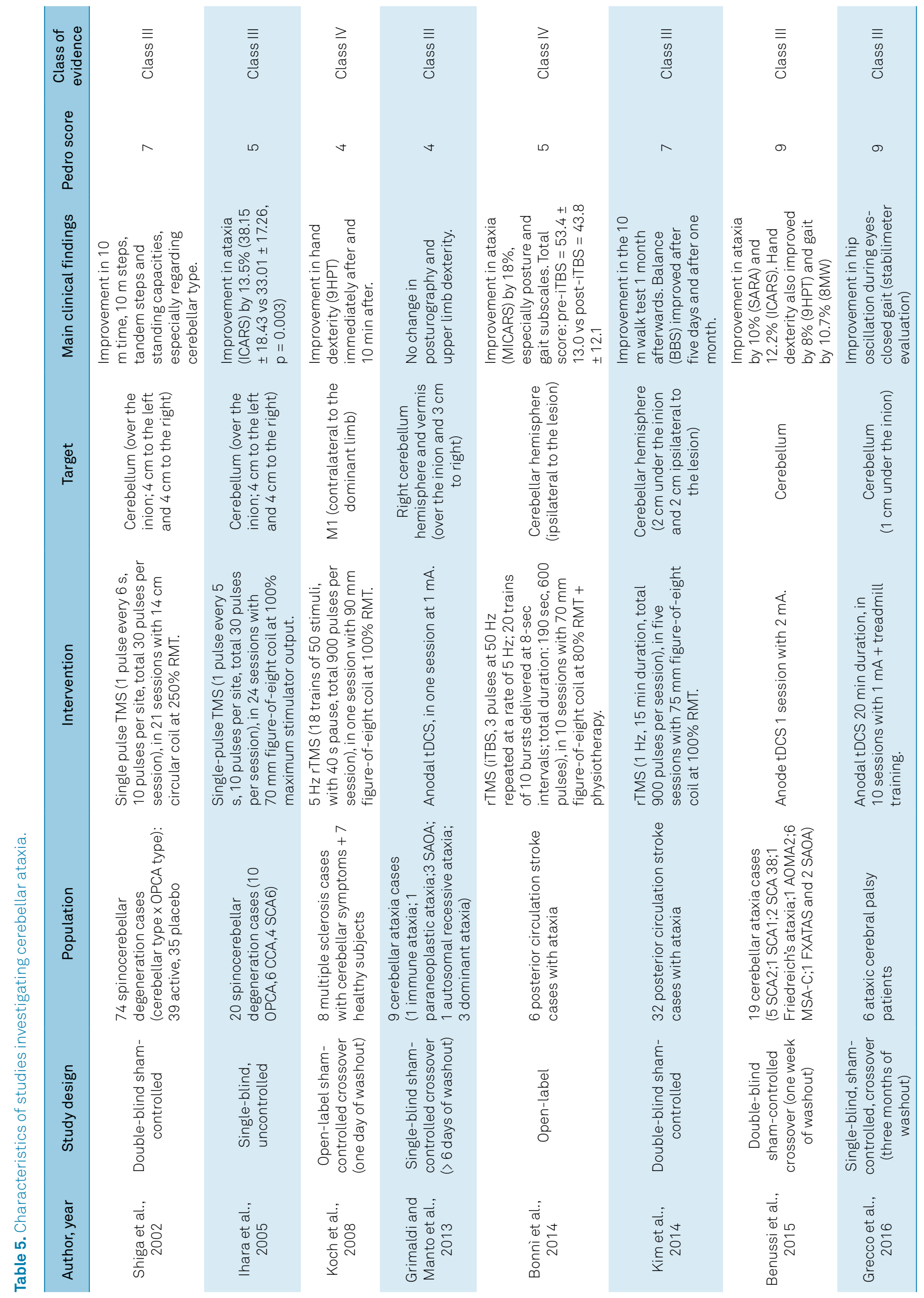




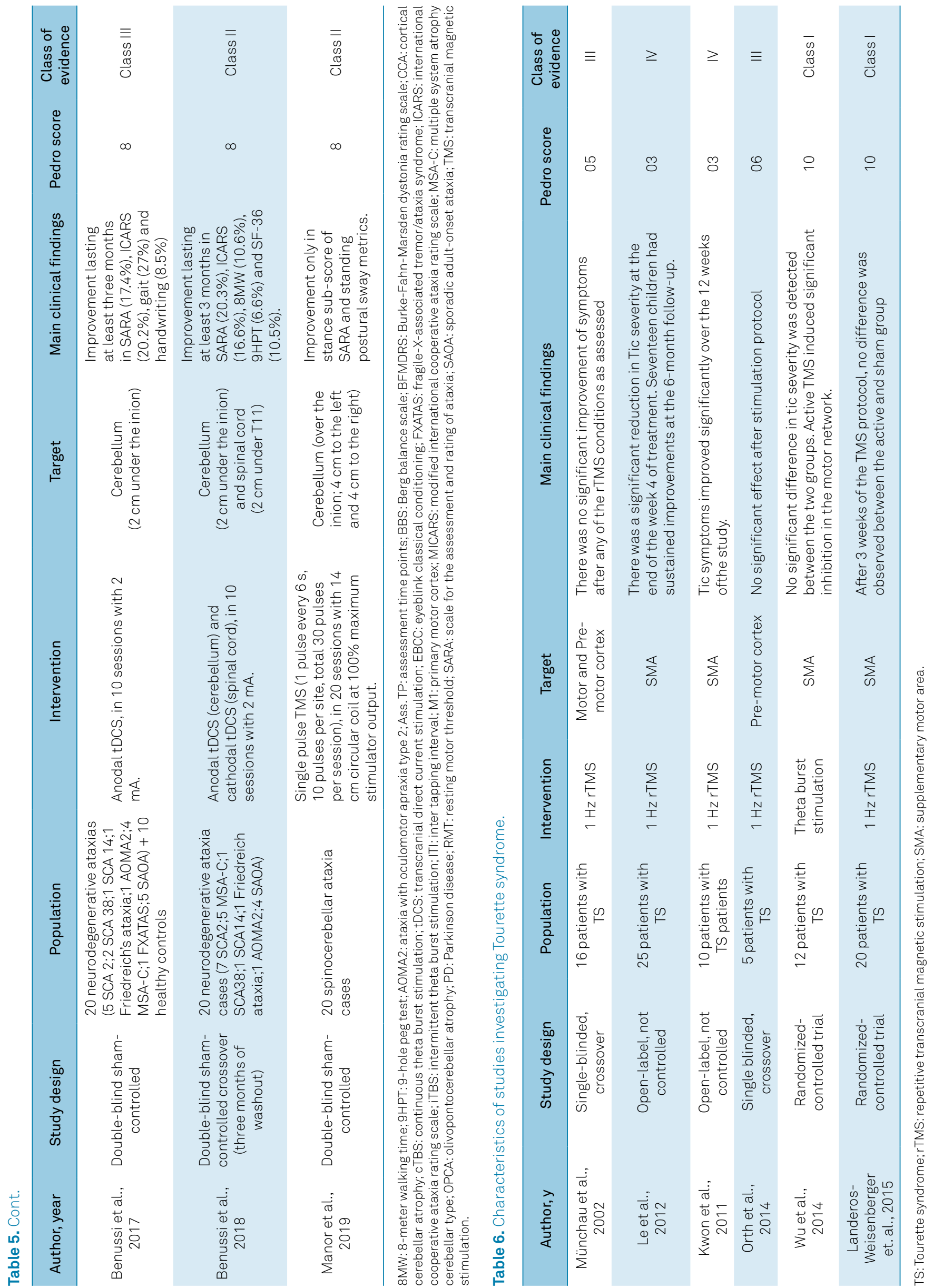


Predictors of efficacy of TMS for TS have been recently discussed, and it has been pointed out that rTMS is more effective in TS with comorbidities (such as obsessive-compulsive disorder and attention deficit hyperactivity disorder), compared with "purer" TS forms ${ }^{70}$. In accordance with the mechanism for TMS, a higher degree of brain electrical activity in individuals with TS and comorbidities (for example, ADHD has been associated with excess theta activity) might constitute a variable that is predictive of good response ${ }^{70}$.

Studies using tDCS in TS are scarce. A recent sham-controlled trial showed that a single session of tDCS over SMA was not effective, with regard to time conditions (pre/post) and stimulation conditions (cathodal/sham), in ten patients ${ }^{77}$.

The mean total PEDro score for the reports on these trials was $6.1(3.1 \pm 3)$. Three studies were considered to present moderate/high quality ( $>5$ points).

\section{Interpretation}

Repetitive TMS over the SMA is likely to be ineffective in reducing tics in TS. The lack of available data regarding other targets and the use of tDCS do not allow any conclusions to be reached regarding these techniques. Two points about the studies need to be addressed. First, the amount of stimulation given (rTMS or tDCS) seems to be an important consideration, since multiple sessions appear to be more effective than a single session. Likewise, a downstream effect from TMS has been demonstrated after repetitive stimulation over the SMA ${ }^{74}$. Second, the high phenotypic variation and comorbidities might have contributed to the disparity of the study outcomes. Besides clinical characteristics, the baseline electrical brain activity has been associated with different TMS responses ${ }^{70}$. How rTMS and tDCS affect this interplay between clinical and electrophysiological patients' characteristics should be addressed in further studies.

\section{Discussion and future directions}

In this review, we have summarized the evidence available regarding noninvasive stimulation therapies for managing the main movement disorders. We found that TMS is likely to be effective for motor symptoms, dyskinesia and depression in PD. Additionally, TMS is possibly effective in improving handwriting in FHD, tremor in ET and cerebellar ataxia and is likely to be ineffective in reducing tics in TS. tDCS is likely to be effective in improving gait in PD.

Despite good results in several studies and the robust background rationale for applying noninvasive stimulation in movement disorders, it remains to be determined how to optimize rTMS and tDCS protocols to give them relevance in routine clinical practice. The best stimulation paradigms and the best responder profiles are still coupled with uncertainties regarding the long-term genuine benefits ${ }^{4}$. Two major factors are determinant. First, there has been large heterogeneity among the protocols used, with different cortical targets and numbers of sessions, which complicates the generalization of the current findings. In comparison, most studies relating to depression have focused on a single recommended site and protocol, producing consistent results. Second, there is still a lack of large-scale trials that could assess the placebo effects of stimulation and the real effects of stimulation in large samples of patients.

\section{Noninvasive stimulation as an add-on therapy}

In our view, because noninvasive stimulation has a low effect size, it should be seen as a "supporting actor," and not as the "leading role". This does not mean that it is less important than rehabilitation or medications, but it thus forms a complementary option, as in the case of botulinum toxin in dystonia or physiotherapy in FoG and ataxia, for example. In this era of personalized medicine, it is of paramount importance to note that noninvasive stimulation will probably serve a subset of patients with a subset of clinical characteristics and specific brain activity abnormalities or network disruption, but not all patients. Additionally, it could be a therapeutic tool for patients for whom surgical approaches are contraindicated, given the safety and lower rate of side effects shown by noninvasive stimulation. Another promising approach is the use of rTMS prior to a training intervention (e.g. prior to physiotherapy if treating gait in PD) or even during a given task in the case of tDCS (e.g. while performing physiotherapy for writer's cramp). In these cases, the rationale is to strengthen the effectiveness of synaptic connections and recruit fibers required to improve performance during a given task?

\section{New stimulation paradigms are needed}

The classical targets explored so far (M1, supplementary area and prefrontal cortex) need to be investigated in multicenter clinical trials, and new paradigms need to be explored with combined or new targets. As discussed earlier, because of the great connectivity of the cerebellum, this has emerged as a potential hot spot for TMS and $\mathrm{tDCS}^{22}$. Along this line, because the spinal cord acts as a 'highway' of neural information and remotely regulates cortical areas relating to the pathophysiology of movement disorders, its modulation is theoretically interesting. A novel approach involving stimulation of the spinal cord noninvasively through a transcutaneous electrical or magnetic field applied to treat spasticity and urinary incontinence has recently emerged ${ }^{7}$. Its applicability is likely to catch the neurology community's attention over the coming years.

Lastly, network dysfunctions in movement disorders are not straightforward and involve multiple supraspinal circuits that are both distinct and overlapping ${ }^{6,8}$. The presence of different underlying circuitries may explain the variability in cortical targets that have been pursued in the literature. An approach involving multiple/combined cortical targets, as recently explored in FoG, may be a key step forward. In 
that investigation, stimulation of the dorsolateral prefrontal cortex simultaneously with M1 induced greater benefit for diminishing FoG severity, compared with M1 stimulation alone ${ }^{7}$.

Noninvasive stimulation approaches have the potential to be successfully applied in clinical practice, either as an adjuvant therapy or as the protagonist in patients with contraindications for other treatments. Large-scale clinical trials focusing on targets previously attempted, from which positive results were obtained, are needed. The best scenario for this developing therapy will probably involve optimization of stimulation protocols, together with new paradigms looking to recruit fibers and neurons during rTMS and tDCS sessions to enhance rehabilitation effects.

\section{ACKNOWLEDGEMENTS}

We would like to thank Paula Starck for designing Figure 1.

\section{SUPPLEMENTARY MATERIAL}

The following material is available online for this article:

S1. PEDro scale - Internal Validity (8 Criteria).

S2. American Academy of Neurology Classification of

Evidence for the Rating of a Therapeutic Study and

Recommendations.

S3. Recommendations based on study classes.

\section{REFERENCES}

1. Edwards MJ, Talelli P, Rothwell JC. Clinical applications of transcranial magnetic stimulation in patients with movement disorders. Lancet Neurol. 2008 Sep;7(9):827-40. https://doi. org/10.1016/S1474-4422(08)70190-X

2. Salinas FS, Lancaster JL, Fox PT. Detailed 3D models of the induced electric field of transcranial magnetic stimulation coils. Phys Med Biol. 2007 May 21;52(10):2879-92. https://doi.org/10.1088/00319155/52/10/016

3. Malenka RC, Bear MF. LTP and LTD: an embarrassment of riches. Neuron. 2004 Sep 30;44(1):5-21. https://doi.org/10.1016/j. neuron.2004.09.012

4. Latorre A, Rocchi L, Berardelli A, et al. The use of transcranial magnetic stimulation as a treatment for movement disorders: a critical review. Mov Disord. 2019 Jun;34(6):769-82. https://doi. org/10.1002/mds. 27705

5. Antal A, Paulus W. Transcranial alternating current stimulation (tACS). Front Hum Neurosci. 2013 Jun 28;7:317. https://doi.org/10.3389/ fnhum.2013.00317

6. Kim SJ, Paeng SH, Kang SY. Stimulation in supplementary motor area versus motor cortex for freezing of gait in Parkinson's disease. J Clin Neurol. 2018 Jul;14(3):320-6. https://doi.org/10.3988/ jcn.2018.14.3.320

7. Cury RG, Carra R, Reis J, Barbosa ER. Optimizing noninvasive stimulation to treat gait problems in Parkinson disease. Arch Phys Med Rehabil. 2020 Jun;101(6):1097-8. https://doi.org/10.1016/j. apmr.2019.10.198

8. Horn A, Reich M, Vorwerk J, et al. Connectivity predicts deep brain stimulation outcome in Parkinson disease. Ann Neurol. 2017 Jul;82(1):67-78. https://doi.org/10.1002/ana.24974

9. Brito M, Teixeira MJ, Mendes MM, et al. Exploring the clinical outcomes after deep brain stimulation in Tourette syndrome. J Neurol Sci. 2019 Jul 15;402:48-51. https://doi.org/10.1016/j.jns.2019.05.011

10. Strafella AP, Paus T, Fraraccio M, Dagher A. Striatal dopamine release induced by repetitive transcranial magnetic stimulation of the human motor cortex. Brain. 2003 Dec;126(12):2609-15. https://doi. org/10.1093/brain/awg268

11. Watanabe T, Hanajima R, Shirota Y, et al. Effects of rTMS of presupplementary motor area on fronto basal ganglia network activity during stop-signal task. J Neurosci. 2015 Mar 25;35(12):4813-23. https://doi.org/10.1523/JNEUROSCI.3761-14.2015

12. Gaynor LMFD, Kühn AA, Dileone M, et al. Suppression of beta oscillations in the subthalamic nucleus following cortical stimulation in humans. Eur J Neurosci. 2008 Oct;28(8):1686-95. https://doi. org/10.1111/j.1460-9568.2008.06363.x
13. Campos TF, Beckenkamp PR, Moseley AM. Usage evaluation of a resource to support evidence-based physiotherapy: the Physiotherapy Evidence Database (PEDro). Physiotherapy. 2013 Sep;99(3):252-7. https://doi.org/10.1016/j.physio.2012.12.001

14. American Academy of Neurology. Appendix C: AAN Classification of evidence for the rating of a therapeutic study. Continuum (Minneap Minn). 2015 Aug;21(4):1169.

15. Li S, Jiao R, Zhou X, Chen S. Motor recovery and antidepressant effects of repetitive transcranial magnetic stimulation on Parkinson disease: a PRISMA-compliant meta-analysis. Medicine (Baltimore). 2020 May;99(18):e19642. https://doi.org/10.1097/ MD.0000000000019642

16. Yang C, Guo Z, Peng H, et al. Repetitive transcranial magnetic stimulation therapy for motor recovery in Parkinson's disease: a Meta-analysis. Brain Behav. 2018 Nov;8(11):e01132. https://doi. org/10.1002/brb3.1132

17. Khedr EM, Mohamed KO, Ali AM, Hasan AM. The effect of repetitive transcranial magnetic stimulation on cognitive impairment in Parkinson's disease with dementia: pilot study. Restor Neurol Neurosci. 2020 Feb 11;38(1):55-66. https://doi.org/10.3233/RNN190956

18. Mi T-M, Garg S, Ba F, et al. High-frequency rTMS over the supplementary motor area improves freezing of gait in Parkinson's disease: a randomized controlled trial. Parkinsonism Relat Disord. 2019 Nov;68:85-90. https://doi.org/10.1016/j.parkreldis.2019.10.009

19. Khedr EM, Al-Fawal B, Wraith AA, et al. The effect of $20 \mathrm{~Hz}$ versus 1 $\mathrm{Hz}$ repetitive transcranial magnetic stimulation on motor dysfunction in Parkinson's disease: which is more beneficial? J Parkinsons Dis. 2019 May 23;9(2):379-87. https://doi.org/10.3233/JPD-181540

20. Hanoğlu L, Saricaoglu M, Toprak G, et al. Preliminary findings on the role of high-frequency $(5 \mathrm{~Hz})$ rTMS stimulation on $\mathrm{M} 1$ and pre-SMA regions in Parkinson's disease. Neurosci Lett. 2020 Apr 17;724:134837. https://doi.org/10.1016/j.neulet.2020.134837

21. Khedr EM, Mohamed KO, Soliman RK, et al. The effect of highfrequency repetitive transcranial magnetic stimulation on advancing Parkinson's disease with dysphagia: double blind randomized clinical trial. Neurorehabil Neural Repair. 2019 Jun;33(6):442-52. https://doi. org/10.1177/1545968319847968

22. França C, de Andrade DC, Teixeira MJ, et al. Effects of cerebellar neuromodulation in movement disorders: a systematic review. Brain Stimulat. 2018 Mar-Apr;11(2):249-60. https://doi.org/10.1016/j. brs.2017.11.015

23. Hai-Jiao W, Ge T, Li-na Z, et al. The efficacy of repetitive transcranial magnetic stimulation for Parkinson disease patients with 
depression. Int J Neurosci. 2020 Jan;130(1):19-27. https://doi.org/10. 1080/00207454.2018.1495632

24. Goodwill AM, Lum JAG, Hendy AM, et al. Using non-invasive transcranial stimulation to improve motor and cognitive function in Parkinson's disease: a systematic review and meta-analysis. Sci Rep. 2017 Nov 1;7(1):14840. https://doi.org/10.1038/s41598-017-13260-z

25. Eggers C, Günther M, Rothwell J, et al. Theta burst stimulation over the supplementary motor area in Parkinson's disease. J Neurol. 2015 Feb;262(2):357-64. https://doi.org/10.1007/s00415-014-7572-8

26. Tard C, Devanne H, Defebvre L, Delval A. Single session intermittent theta-burst stimulation on the left premotor cortex does not alleviate freezing of gait in Parkinson's disease. Neurosci Lett. 2016 Aug 15;628:1-9. https://doi.org/10.1016/j.neulet.2016.05.061

27. Hill AT, McModie S, Fung W, et al. Impact of prefrontal intermittent theta-burst stimulation on working memory and executive function in Parkinson's disease: A double-blind sham-controlled pilot study. Brain Res. 2020 Jan 1;1726:146506. https://doi.org/10.1016/j. brainres.2019.146506

28. Orrù G, Baroni M, Cesari V, et al. The effect of single and repeated tDCS sessions on motor symptoms in Parkinson's disease: a systematic review. Arch Ital Biol. 2019 Sep 30;157(2-3):89-101. https://doi.org/10.12871/aib.v157i2-3.4707

29. Simpson MW, Mak M. The effect of transcranial direct current stimulation on upper limb motor performance in Parkinson's disease: a systematic review. J Neurol. 2020 Dec;267(12):3479-88. https://doi. org/10.1007/s00415-019-09385-y

30. Lee HK, Ahn SJ, Shin YM, et al. Does transcranial direct current stimulation improve functional locomotion in people with Parkinson's disease? a systematic review and meta-analysis. J Neuroeng Rehabil. 2019 Jul 8;16(1):84. https://doi.org/10.1186/s12984-019-0562-4

31. Albanese A, Bhatia K, Bressman SB, et al. Phenomenology and classification of dystonia: a consensus update. Mov Disord. 2013 Jun 15;28(7)863-73. https://doi.org/10.1002/mds.25475

32. Thompson VB, Jinnah HA, Hess EJ. Convergent mechanisms in etiologically-diverse dystonias. Expert Opin Ther Targets. 2011 Dec;15(12):1387-403. https://doi.org/10.1517/14728222.2011.6415 33

33. Siebner HR, Filipovic SR, Rowe JB, et al. Patients with focal arm dystonia have increased sensitivity to slow-frequency repetitive TMS of the dorsal premotor cortex. Brain. 2003 Dec;126(12):2710-25. https://doi.org/10.1093/brain/awg282

34. Siebner HR, Tormos JM, Ceballos-Baumann AO, et al. Low-frequency repetitive transcranial magnetic stimulation of the motor cortex in writer's cramp. Neurology. 1999 Feb;52(3):529-37. https://doi. org/10.1212/WNL.52.3.529

35. Kimberley TJ, Borich MR, Arora S, Siebner HR. Multiple sessions of low-frequency repetitive transcranial magnetic stimulation in focal hand dystonia: clinical and physiological effects. Restor Neurol Neurosci. 2013;31(5):533-42. https://doi.org/10.3233/RNN-120259

36. Bradnam LV, Graetz LJ, McDonnell MN, Ridding MC. Anodal transcranial direct current stimulation to the cerebellum improves handwriting and cyclic drawing kinematics in focal hand dystonia. Front Hum Neurosci. 2015 May 18;9:286. https://doi.org/10.3389/ fnhum.2015.00286

37. Rosset-Llobet J, Fàbregas-Molas S, Pascual-Leone Á. Effect of transcranial direct current stimulation on neurorehabilitation of task-specific dystonia: a double-blind, randomized clinical trial. Med Probl Perform Art. 2015 Sep 1;30(3):178-84. https://doi. org/10.21091/mppa.2015.3033

38. Furuya S, Nitsche MA, Paulus W, Altenmüller E. Surmounting retraining limits in musicians' dystonia by transcranial stimulation. Ann Neurol. 2014 May;75(5):700-7. https://doi.org/10.1002/ ana.24151
39. Buttkus F, Weidenmüller M, Schneider S, et al. Failure of cathodal direct current stimulation to improve fine motor control in musician's dystonia: cathodal tDCS as a treatment for focal dystonia? Mov Disord. 2010 Feb 15;25(3):389-94. https://doi.org/10.1002/ mds. 22938

40. Buttkus F, Baur V, Jabusch H-C, et al. Single-session tDCS-supported retraining does not improve fine motor control in musician's dystonia. Restor Neurol Neurosci. 2011;29(2):85-90. https://doi.org/10.3233/ RNN-2011-0582

41. Murase N, Rothwell JC, Kaji R, et al. Subthreshold low-frequency repetitive transcranial magnetic stimulation over the premotor cortex modulates writer's cramp. Brain. 2005 Jan;128(1):104-15. https://doi. org/10.1093/brain/awh315

42. Borich M, Arora S, Kimberley TJ. Lasting effects of repeated rTMS application in focal hand dystonia. Restor Neurol Neurosci. 2009 Jan 1;27(1):55-65. https://doi.org/10.3233/RNN-2009-0461

43. Huang Y-Z, Lu C-S, Rothwell JC, et al. Modulation of the disturbed motor network in dystonia by multisession suppression of premotor cortex. PLoS One. 2012 Oct 10;7(10):e47574. https://doi.org/10.1371/ journal.pone.0047574

44. Havrankova P, Jech R, Walker ND, et al. Repetitive TMS of the somatosensory cortex improves writer's cramp and enhances cortical activity. Neuro Endocrinol Lett. 2010;31(1):73-86.

45. Koch G, Porcacchia P, Ponzo V, et al. Effects of two weeks of cerebellar theta burst stimulation in cervical dystonia patients. Brain Stimul. 2014 Jul-Aug;7(4):564-72. https://doi.org/10.1016/j.brs.2014.05.002

46. Richardson SP, Tinaz S, Chen R. Repetitive transcranial magnetic stimulation in cervical dystonia: effect of site and repetition in a randomized pilot trial. PLoS One. 2015 Apr 29;10(4):e0124937. https:// doi.org/10.1371/journal.pone.0124937

47. Kranz G, Shamim EA, Lin PT, et al. Transcranial magnetic brain stimulation modulates blepharospasm: a randomized controlled study. Neurology. 2010 Oct 19;75(16):1465-71. https://doi. org/10.1212/WNL.0b013e3181f8814d

48. Gironell A, Kulisevsky J, Lorenzo J, et al. Transcranial magnetic stimulation of the cerebellum in essential tremor: a controlled study. Arch Neurol. 2002 Mar;59(3):413-7. https://doi.org/10.1001/ archneur.59.3.413

49. Avanzino L, Bove M, Tacchino A, et al. Cerebellar involvement in timing accuracy of rhythmic finger movements in essential tremor. Eur J Neurosci. 2009 Nov;30(10):1971-9. https://doi.org/10.1111/ j.1460-9568.2009.06984.x

50. Hellriegel H, Schulz EM, Siebner HR, et al. Continuous theta-burst stimulation of the primary motor cortex in essential tremor. Clin Neurophysiol. 2012 May;123(5):1010-5. https://doi.org/10.1016/j. clinph.2011.08.033

51. Popa T, Russo M, Vidailhet M, et al. Cerebellar rTMS stimulation may induce prolonged clinical benefits in essential tremor, and subjacent changes in functional connectivity: an open label trial. Brain Stimul. 2013 Mar 1;6(2):175-9. https://doi.org/10.1016/j.brs.2012.04.009

52. Gironell A, Martínez-Horta S, Aguilar S, et al. Transcranial direct current stimulation of the cerebellum in essential tremor: a controlled study. Brain Stimul. 2014 May 1;7(3):491-2. https://doi. org/10.1016/j.brs.2014.02.001

53. Chuang W-L, Huang Y-Z, Lu C-S, Chen R-S. Reduced cortical plasticity and GABAergic modulation in essential tremor. Mov Disord. 2014 Apr;29(4):501-7. https://doi.org/10.1002/mds.25809

54. Bologna M, Rocchi L, Leodori G, et al. Cerebellar continuous theta burst stimulation in essential tremor. Cerebellum. 2015 Apr;14(2):133-41. https://doi.org/10.1007/s12311-014-0621-0

55. Badran BW, Glusman CE, Austelle CW, et al. A double-blind, shamcontrolled pilot trial of pre-supplementary motor area (Pre-SMA) $1 \mathrm{~Hz}$ rTMS to treat essential tremor. Brain Stimul. 2016 Nov 1;9(6):945-7. 
56. Shin H-W, Hallett M, Sohn YH. Cerebellar repetitive transcranial magnetic stimulation for patients with essential tremor. Parkinsonism Relat Disord. 2019 Jul 1;64:304-7. https://doi. org/10.1016/j.parkreldis.2019.03.019

57. Manor B, Greenstein PE, Davila-Perez P, et al. Repetitive transcranial magnetic stimulation in spinocerebellar ataxia: a pilot randomized controlled trial. Front Neurol. 2019 Feb 12;10:73. https://doi. org/10.3389/fneur.2019.00073

58. Benussi A, Dell'Era V, Cantoni V, et al. Cerebello-spinal tDCS in ataxia: a randomized, double-blind, sham-controlled, crossover trial. Neurology. 2018 Sep 18;91(12):e1090-101. https://doi.org/10.1212/ WNL.0000000000006210

59. Benussi A, Koch G, Cotelli M, et al. Cerebellar transcranial direct current stimulation in patients with ataxia: a doubleblind, randomized, sham-controlled study. Mov Disord. 2015 Oct;30(12):1701-5. https://doi.org/10.1002/mds.26356

60. Bonnì S, Ponzo V, Caltagirone C, Koch G. Cerebellar theta burst stimulation in stroke patients with ataxia. Funct Neurol. $2014 \mathrm{Jan}-$ Mar;29(1):41-5.

61. Kim W-S, Jung SH, Oh MK, et al. Effect of repetitive transcranial magnetic stimulation over the cerebellum on patients with ataxia after posterior circulation stroke: a pilot study. J Rehabil Med. 2014 May;46(5):418-23. https://doi.org/10.2340/16501977-1802

62. Koch G, Rossi S, Prosperetti C, et al. Improvement of hand dexterity following motor cortex rTMS in multiple sclerosis patients with cerebellar impairment. Mult Scler. 2008 Aug;14(7):995-8. https://doi. org/10.1177/1352458508088710

63. Grecco L, Duarte NAC, Marques V, et al. Cerebellar transcranial direct current stimulation in a child with ataxic cerebral palsy: a case report. Gait Posture. 2015 Sep;42 Suppl 1:S93-4. https://doi. org/10.1016/j.gaitpost.2015.06.171

64. Shimizu H, Tsuda T, Shiga Y, et al. Therapeutic efficacy of transcranial magnetic stimulation for hereditary spinocerebellar degeneration. Tohoku J Exp Med. 1999 Nov;189(3):203-11. https://doi.org/10.1620/ tjem.189.203

65. Shiga Y, Tsuda T, Itoyama Y, et al. Transcranial magnetic stimulation alleviates truncal ataxia in spinocerebellar degeneration.J Neurol Neurosurg Psychiatry. 2002 Jan;72(1):124-6. https://doi.org/10.1136/ jnnp.72.1.124

66. Ihara $\mathrm{Y}$, Takata $\mathrm{H}$, Tanabe $\mathrm{Y}$, et al. Influence of repetitive transcranial magnetic stimulation on disease severity and oxidative stress markers in the cerebrospinal fluid of patients with spinocerebellar degeneration. Neurol Res. 2005 Apr;27(3):310-3. https://doi. org/10.1179/016164105X39897
67. Grimaldi G, Manto M. Anodal transcranial direct current stimulation (tDCS) decreases the amplitudes of long-latency stretch reflexes in cerebellar ataxia. Ann Biomed Eng. 2013 Nov;41(11):2437-47. https:// doi.org/10.1007/s10439-013-0846-y

68. Benussi A, Dell'Era V, Cotelli MS, et al. Long term clinical and neurophysiological effects of cerebellar transcranial direct current stimulation in patients with neurodegenerative ataxia. Brain Stimul. 2017 Mar 1;10(2):242-50. https://doi.org/10.1016/j.brs.2016.11.001

69. Benussi A, Dell'Era V, Cantoni V, et al. Cerebello-spinal tDCS in ataxia: a randomized, double-blind, sham-controlled, crossover trial. Neurology. 2018 Sep 18;91(12):e1090-101. https://doi.org/10.1212/ WNL.0000000000006210

70. Grados M, Huselid R, Duque-Serrano L. Transcranial magnetic stimulation in tourette syndrome: a historical perspective, its current use and the influence of comorbidities in treatment response. Brain Sci. 2018 Jul 6;8(7):129. https://doi.org/10.3390/brainsci8070129

71. Le K, Liu L, Sun M, et al. Transcranial magnetic stimulation at 1 Hertz improves clinical symptoms in children with Tourette syndrome for at least 6 months. J Clin Neurosci. 2013 Feb 1;20(2):257-62. https://doi. org/10.1016/j.jocn.2012.01.049

72. Kwon HJ, Lim WS, Lim MH, et al. 1-Hz low frequency repetitive transcranial magnetic stimulation in children with Tourette's syndrome. Neurosci Lett. 2011 Mar 29;492(1):1-4. https://doi. org/10.1016/j.neulet.2011.01.007

73. Wu SW, Maloney T, Gilbert DL, et al. Functional MRI-navigated repetitive transcranial magnetic stimulation over supplementary motor area in Chronic Tic Disorders. Brain Stimulat. 2014 MarApr;7(2):212-8. https://doi.org/10.1016/j.brs.2013.10.005

74. Landeros-Weisenberger A, Mantovani A, Motlagh MG, et al. Randomized sham controlled double-blind trial of repetitive transcranial magnetic stimulation for adults with severe Tourette syndrome. Brain Stimulat. 2015 May 1;8(3):574-81. https://doi. org/10.1016/j.brs.2014.11.015

75. Orth M, Kirby R, Richardson MP, et al. Subthreshold rTMS over pre-motor cortex has no effect on tics in patients with Gilles de la Tourette syndrome. Clin Neurophysiol. 2005 Apr;116(4):764-8. https://doi.org/10.1016/j.clinph.2004.10.003

76. Munchau A, Bloem BR, Thilo KV, et al. Repetitive transcranial magnetic stimulation for Tourette syndrome. Neurology. 2002 Dec 10;59(11):1789-91. https://doi.org/10.1212/01. WNL.0000036615.25044.50

77. Dyke K, Jackson GM, Nixon E, Jackson SR. Effects of single-session cathodal transcranial direct current stimulation on tic symptoms in Tourette's syndrome. Exp Brain Res. 2019 Nov;237(11):2853-63. https://doi.org/10.1007/s00221-019-05637-5 